\title{
Effect of Oatmeal as a Fat Replacer on Physical Properties and Sensory Acceptance of Creamy Salad Dressing
}

\author{
Nutsuda Sumonsiri ${ }^{1, *}$, Benjaporn Panjun ${ }^{1}$, Supanna Naksuk $^{1}$, Sarisara Boonmawat ${ }^{1}$, Amornrat Mukprasirt $^{1}$, and \\ Pattama Phasuthan ${ }^{1}$ \\ ${ }^{1}$ Department of Agro-Industrial, Food, and Environmental Technology, Faculty of Applied Science, King Mongkut's University of \\ Technology North Bangkok, Bangkok, Thailand
}

\begin{abstract}
Overconsumption of fat leads to cardiovascular diseases and other health problems; therefore, consumers prefer diets with high fiber and low fat content for their healthy weight management. Fat replacers can be potentially applied in several foods but they can affect appearance, texture, rheology, and flavor of emulsion products. This research aimed to study the effect of oatmeal as a fat replacer on creamy salad dressing $(53.39 \%(\mathrm{w} / \mathrm{w})$ refined soybean oil, $20.20 \%(\mathrm{w} / \mathrm{w})$ sweetened condensed milk, $12.99 \%(\mathrm{w} / \mathrm{w})$ distilled vinegar, $8.08 \%(\mathrm{w} / \mathrm{w})$ egg yolk, $4.33 \%(\mathrm{w} / \mathrm{w})$ refined sugar, $0.58 \%(\mathrm{w} / \mathrm{w})$ iodized salt, and $0.43 \%(\mathrm{w} / \mathrm{w})$ mustard). The oatmeal was used to partially replace soybean oil in the product at $3.61,7.22$, $10.82,14.43,18.04$, and $21.65 \%(\mathrm{w} / \mathrm{w})$. After preparation, fat content, protein content, apparent viscosity, and sensory acceptance of control and fat-reduced samples were evaluated. Fat replacing with oatmeal led to decreasing of fat content but increasing of protein content and apparent viscosity. At $21.65 \%$ fat replacement, there was $33.13 \%$ fat reduction compared to the control sample. In sensory evaluation by 30 untrained panelists, reduced-fat creamy salad dressing had the same or higher acceptance scores in appearance, color, texture, aftertaste, and overall acceptance. Oatmeal can be an alternative fat replacer in reduced-fat creamy salad dressing.
\end{abstract}

\section{Introduction}

Salad dressings are semisolid oil-in-water emulsions served with salad for flavor enhancement and modification [1]. Since consumers tend to prefer readyto-eat fruit- and vegetable-based diets for their convenience, good health and weight management, the compound annual growth rate of global salad dressing market is expected at approximately $6.3 \%$ from USD 90,700 million in 2019 to USD 130,900 million in 2024 [2-4]. Salad dressing products can be classified into 2 main types: spoonable salad dressing (such as mayonnaise) and pourable salad dressing (such as creamy salad dressing or salad cream) [5].

Creamy salad dressing is a yellow pourable viscous sauce usually made of vegetable oil, distilled vinegar, sugar, egg yolks, mustard, modified starch, water, and salt. Stabilizers, such as xanthan gum and guar gum, can also be added to provide viscosity and prevent syneresis [5]. The previous research showed that consumption of salad dressing leads to intake of fat and cholesterol [6] since there are vegetable oil (at least 30\%) and liquid egg yolk $(4 \%)$ as main ingredients [7, 8]. Overconsumption of fat can result in health problems and obesity; therefore, food products with reduction of fat, cholesterol, salt, and calorie contents tend to be highly preferable, especially among those consumers with health concerns. When fat is removed from salad dressing, one of challenges is an undesirable change in stability, texture, flavor, and physicochemical properties of the products [9]. In consequence, fat substitutes, such as gums, modified starch, whey protein concentrates, are added to enhance texture and prevent gravitational separation of salad dressing [9, 10].

Oatmeal is colloidal extract produced by boiling finely ground oat [11]. All oatmeal, either produced with standard, quick or instant oats, is considered as whole grain [12]. Oat (Avena stiva L.) is the sixth rank in cereal production in the world [13]. Oat grains consist of $66.3 \%$ carbohydrate, $16.9 \%$ protein, $10.6 \%$ dietary fiber, $6.9 \%$ fat (no cholesterol), and 4\% $\beta$-glucan (soluble fiber) [13, 14]. The popularity of oatmeal and oat products has increased after the Food and Drug Administration (FDA) allowed food producers to include health claims that their products contain soluble fiber from whole oats on a food label and the risk of heart disease may be reduced by consuming $3.0 \mathrm{~g}$ of soluble fiber a day [13]. Several epidermiologic reports also revealed that consumption of whole-grains ( $\geq 3$ servings daily) can reduce the risks for diabetes, cardiovascular disease, and obesity due to the reduction of total cholesterol (TC) and low-density lipoprotein cholesterol (LDL-C). It is believed that $\beta$-glucan in oats can increase excretion of bile acid, leading to reduction of cholesterol circulating concentrations [12].

Oat and oatmeal have been studied as a fat replacer in many types of food products, such as sausages, chicken nuggets, ice cream, yogurt, and mayonnaise [1521]. In low-fat sausages made with beef, pork, and chicken, addition of $10 \%$ oatmeal can reduce cooking

\footnotetext{
* Corresponding author: nutsuda.s@sci.kmutnb.ac.th
} 
loss and soften the product texture [15]; however, addition of wheat fiber, oat fiber, and inulin increases hardness of Chinese-style sausages without affecting color and chemical composition of the product [16]. Another study has recently shown effect of oat flour in low-fat chicken nuggets. Levels of oat flour addition have a significant impact on texture, chemical compositions, and sensory acceptance of the product [17]. Partially replacing fat with oat in ice cream also increases fiber content and antioxidant activity of the product [18]. Moreover, oat $\beta$-glucan and oat fiber have positive effects on viscosity and water-holding capacity of camel yogurt and apricot probiotic drinking yogurt, respectively $[19,20]$. In mayonnaise, addition of oat dextrin at $27.9 \%$ substituted rate for fat can lead to the increase of viscosity and decrease of calorie value while product is still acceptable in sensory evaluation [21]. The objective of this research was to study the application of oatmeal as a fat replacer in creamy salad dressing, focusing on its effects on physical properties and sensory acceptance of the product.

\section{Materials and methods}

\subsection{Oatmeal and creamy salad dressing preparation}

Instant oat (McGarrett, Continental Food Co., Ltd., Bangkok, Thailand) was mixed with warm water $\left(75^{\circ} \mathrm{C}\right)$ by a magnetic stirrer. The ratio of oat and water was 1:5.5. The oatmeal was cooled down to $30^{\circ} \mathrm{C}$ prior to applying in creamy salad dressing.

A control sample of creamy salad dressing consisted of $53.39 \%(\mathrm{w} / \mathrm{w})$ refined soybean oil (Cook, Thanakorn Vegetable Oil Products Co., Ltd., Samutprakarn, Thailand), $20.20 \%$ (w/w) sweetened condensed milk (Mali, The Thai Dairy Industry Co., Ltd., Bangkok, Thailand), $12.99 \%(\mathrm{w} / \mathrm{w})$ distilled vinegar (Golden Mountain, ThaiTheparos Public Company Limited, Samutprakarn, Thailand), 8.08\% (w/w) egg yolk (CP, CP All Public Company Limited, Bangkok, Thailand), $4.33 \%$ (w/w) refined sugar (Lin, Thai Roong Ruang Group, Bangkok, Thailand), $0.58 \%(\mathrm{w} / \mathrm{w})$ iodized salt (Prung Thip, Thai Refined Salt Co., Ltd., Bangkok, Thailand), and $0.43 \%$ (w/w) mustard (Heinz, Kraft Heinz Company, Mendota Heights, MN, USA). First, egg yolk was mixed with sweetened condensed milk at speed no.1 using a mixer (Tefal, Indonesia) for $60 \mathrm{sec}$. Then, soybean oil was added and mixed at speed no. 1 for $120 \mathrm{sec}$ and speed no. 2 for $45 \mathrm{sec}$. After that, sugar, salt, and vinegar were added and mixed at speed no. 1 for $80 \mathrm{sec}$. Finally, mustard was added and mixed at speed no. 1 for $10 \mathrm{sec}$ and speed no. 2 for $10 \mathrm{sec}$.

All treatments were prepared using the same procedures as a control described above except that soybean oil was partially replaced with oatmeal at 3.61, $7.22,10.82,14.43,18.04$, and $21.65 \%(w / w)$. However, oatmeal was added in the last order and mixed at speed no. 1 for $90 \mathrm{sec}$ and speed no. 2 for $20 \mathrm{sec}$.

All control and reduced-fat samples were prepared at ambient temperature $\left(25 \pm 3^{\circ} \mathrm{C}\right)$. After preparation, they were pasteurized at $75^{\circ} \mathrm{C}$ for $5 \mathrm{~min}$ and then kept in a refrigerator at $4^{\circ} \mathrm{C}$ for $24 \mathrm{~h}$ prior to further analysis. The sample preparation was repeated independently as three replications on different days.

\subsection{Determination of fat and protein contents}

Fat and protein contents were determined according to AOAC official methods no. 963.15 and 991.20 [22], respectively. All samples were placed outside the refrigerator to equilibrate to room temperature and then analysed at $25 \pm 3^{\circ} \mathrm{C}$.

\subsection{Apparent viscosity measurement}

Apparent viscosity of creamy salad dressing was measured at $25 \pm 3^{\circ} \mathrm{C}$ using a Brookfield rotational rheometer (Brookfield DV-II+, Brookfield Engineering Laboratories, Inc., Massachusetts, U.S.A.) equipped with an interchangeable disc spindle (no.6). All samples were placed outside the refrigerator to equilibrate to room temperature and then analysed at $25 \pm 3^{\circ} \mathrm{C}$. The readings of apparent viscosity of samples $(400 \mathrm{~mL}$ in $500 \mathrm{~mL}$ beaker) were taken at rotational speed at $50 \mathrm{rpm}$ for $1 \mathrm{~min}$. The spindle no. 6 and speed of $50 \mathrm{rpm}$ had been chosen as the most suitable spindle and rotational speed respectively during preliminary experiments.

\subsection{Sensory evaluation}

Control and three reduced-fat samples (selected from samples with appropriate fat content, protein content, and apparent viscosity) were evaluated for acceptance in appearance, color, texture, aftertaste, and overall acceptance using a 7-point hedonic scale, including 1 (dislike very much), 2 (dislike moderately), 3 (dislike slightly), 4 (neither like nor dislike), 5 (like slightly), 6 (like moderately), 7 (like very much). In this evaluation, there were 30 untrained panelists screened from undergraduate students in the Department of Agro-Industrial, Food, and Environmental Technology, Faculty of Applied Science, King Mongkut's University of Technology North Bangkok (KMUTNB), Thailand. All samples were labelled using random 3-digit codes and presented in a randomized complete block design. The presentation order was also randomized using the random number generator to reduce sample order effects. During the evaluation, panelists were asked to evaluate the samples with crackers, served as shown in Fig. 1. After testing each sample, they needed to cleanse their mouths with warm water to eliminate the taste of the previous sample.

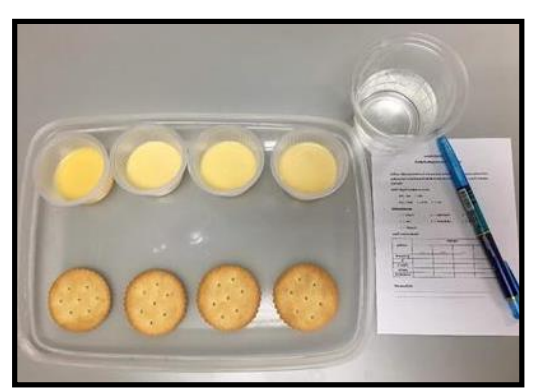

Fig. 1. Presentation of control and reduced-fat samples in sensory evaluation 


\subsection{Statistical analysis}

All analyses were performed in triplicate with three subsamples. Significant differences among means at $\mathrm{p}<0.05$ were analysed by one-way analysis of variance (one-way ANOVA) and Duncan's multiple range test using IBM SPSS Statistics 21 (IBM Corporation, Armonk, NY, USA).

\section{Results and discussion}

\subsection{Fat content}

Fat content of creamy salad dressing significantly decreased as concentration of oatmeal increased $(p<0.05)$ (Fig. 2). The lowest fat content $(40.66 \pm 2.4 \%)$ was obtained when replacing soybean oil with oatmeal at $21.65 \%$, accounting for $33.13 \%$ fat reduction compared to the control sample (with fat content of $60.80 \pm 1.25 \%$ ) while fat content in commercial salad cream dressing is approximately $53 \%$ [23]. There is $93.3 \%(\mathrm{w} / \mathrm{v})$ total fat in the soybean oil used in this research while oat contains only $6.9 \%(\mathrm{w} / \mathrm{w})$ total fat [13]. Even though oat grains have higher lipid levels than other cereal grains, there are high levels of unsaturated fatty acids (78-81.5\% of total fatty acids), including 38.4-41.6\% linoleic acid [24], which are essential fatty acids required for energy and hormone production, as well as synthesis of intracellular signaling molecules and cell membrane [25]. The decrease of fat content in fat-reduced creamy salad dressing with oatmeal may happen due to capability of phenolic compounds in oat to prevent cholesterol and DHA oxidation during heating or cooking, resulting in reducing the production of toxic products from cholesterol oxidation and the risk for health problems [26].

Similar results of decreasing in fat content in the product with addition of oat were found in replacing $10 \%$ fat with oat emulsion gels in fresh sausages [27], replacing $10 \%$ fat with hydrated oatmeal in sausages made with beef, pork, and chicken [15], and adding up to $10 \%$ oat flour over the amount of chicken meat in lowfat chicken nuggets [17]. Moreover, $2 \%$ fat replacement with oat could decrease fat content in ice cream [18].

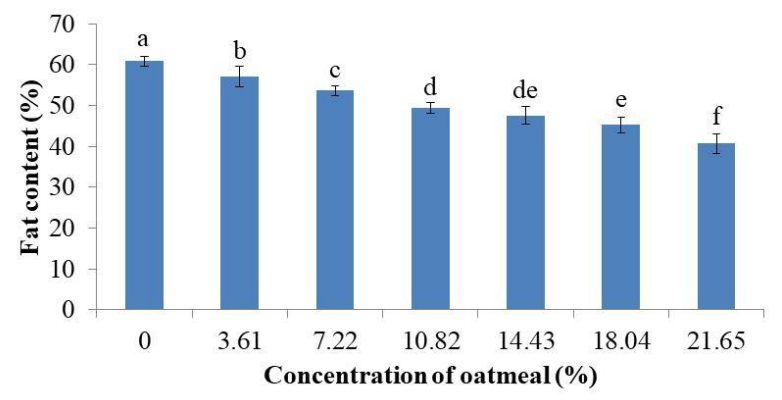

Fig. 2. Fat content of creamy salad dressing with different concentrations of oat meal. Different letters (a, b, c, d, e, and f) indicate significant difference among samples at $\mathrm{p}<0.05(\mathrm{n}=3$, error bars: standard deviations).

\subsection{Protein content}

As concentration of oatmeal increased, protein content of creamy salad dressing tended to increase (Fig. 3). The sample with $21.65 \%$ oatmeal replacement had $39.58 \%$ higher protein content when compared to the control sample (with protein content of $1.44 \pm 0.24 \%$ ) while there is no protein in commercial salad cream dressing [23]. There is $16.9 \%$ protein in oat grains [13] where $80 \%$ of total proteins are globulins (soluble in salt water); $15 \%$ of total proteins are prolamins (soluble in dilute alcohol solution); $5-66 \%$ of total proteins are glutelins (soluble in acids or bases); and $1-12 \%$ of total proteins are albumins (water soluble) [28]. According to European commission regulation (EC) No. 41/2009, oats are officially gluten free since the gluten content does not exceed $20 \mathrm{mg} / \mathrm{kg}$ [29]. The products in this research could be safely consumable for celiac patients. Moreover, some essential amino acids which can be found in oat grains are arginine $(9.78-10.88 \mathrm{~g} / \mathrm{kg}$ ), leucine $(9.17-10.18 \mathrm{~g} / \mathrm{kg})$, valine $(6.01-6.98 \mathrm{~g} / \mathrm{kg})$, phenylalanine $(5.56-6.50 \mathrm{~g} / \mathrm{kg}$ ), and isoleucine (4.41$5.10 \mathrm{~g} / \mathrm{kg})[24]$.

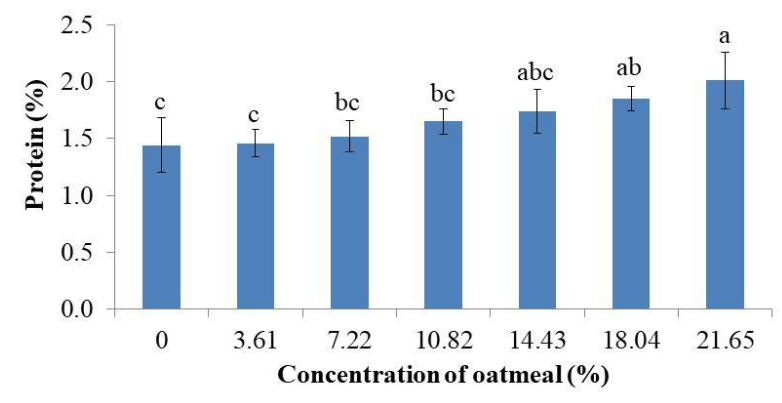

Fig. 3. Protein content of creamy salad dressing with different concentrations of oat meal. Different letters (a, b, and c) indicate significant difference among samples at $\mathrm{p}<0.05 \quad(\mathrm{n}=3$, error bars: standard deviations).

The opposite results can be observed in fat replacing of oatmeal in low-fat sausages made of beef, pork, and chicken since only $10 \%$ hydrated oatmeal was used to substitute meat content in the sausage formulation [15]. However, protein contents in fresh sausages [27] and Chinese-style sausages [16] were not significantly different from the control products $(\mathrm{p} \geq 0.05)$ when oat emulsion gels and oat fiber were added respectively.

\subsection{Apparent viscosity}

Apparent viscosity of creamy salad dressing tended to increase when more oatmeal was used to replace soybean oil in the product (Fig. 4). Oat is considered as a cereal with good source of $\beta$-glucan, which is responsible for the increase apparent viscosity of the product [13]. The apparent viscosity of creamy salad dressing with oatmeal added in this research ranged from $5,750.00 \pm 536.75$ to $6,726.67 \pm 540.12 \mathrm{cP}$ while the beverage with $1 \%$ oat $\beta$-glucan had apparent viscosity from 1,223 to $4,162 \mathrm{cP}$ at shear rate from $100 / \mathrm{sec}$ to $16 / \mathrm{sec}$ [30]. 


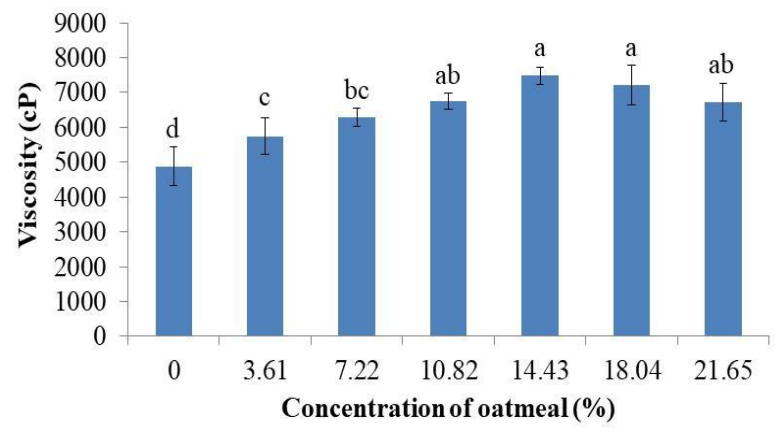

Fig. 4. Apparent viscosity of creamy salad dressing with different concentrations of oat meal. Different letters (a, b, and c) indicate significant difference among samples at $\mathrm{p}<0.05$ $(n=3$, error bars: standard deviations).

It is believed that $\beta$-glucan, which is polysaccharide found in the endosperm cell wall in oats, can create a network of protein-polysaccharide, leading to the increase of viscosity [19]. $\beta$-glucan can also increase water-holding capacity and water retention ability of emulsion products since cellulosic regions in the polymer contain hydrogen bond and form junction zones where water is trapped, resulting in gel formation and higher viscosity [31].

Similar results for positive effect of oat on apparent viscosity have also been observed in fat-reduced ice cream mixes containing $2 \%$ oat as a fat replacer [18]. Another study found positive correlation of oat $\beta$-glucan and viscosity of oat $\beta$-glucan-milk mixtures [32]. In addition, non-fat set yogurt with oat $\beta$-glucan has firmer and stickier texture when compared to the yogurt without oat $\beta$-glucan [33]. Moreover, addition of $1-2 \%(w / v)$ oat $\beta$-glucan and $0.5-2.0 \%$ oat fiber can increase waterholding capacity and viscosity of camel yogurt [19] and apricot probiotic drinking yogurt [20] respectively.

\subsection{Sensory evaluation}

The creamy salad dressings with 14.43, 18.04, and $21.65 \%$ oatmeal were selected for the sensory evaluation due to their low fat content, as well as high protein content and apparent viscosity. The acceptance test with 7-hedonic scale was conducted to determine consumer acceptability on fat-reduced creamy salad dressing among untrained panelists $(n=30)$, compared to the control sample. Acceptance scores on appearance, color, texture, aftertaste, and overall acceptance are presented in Fig. 5. There was no significant difference among samples in the acceptance of appearance and texture $(\mathrm{p} \geq 0.05)$. In the acceptance of color, panelists preferred fat-reduced creamy salad dressing supplemented with oatmeal to the control sample $(\mathrm{p}<0.05)$. In the acceptance in aftertaste and overall acceptance, the fatreduced products had the same or higher scores than the control sample. All fat-reduced samples obtained the acceptance scores of approximately ' 5 ' or 'like slightly'.

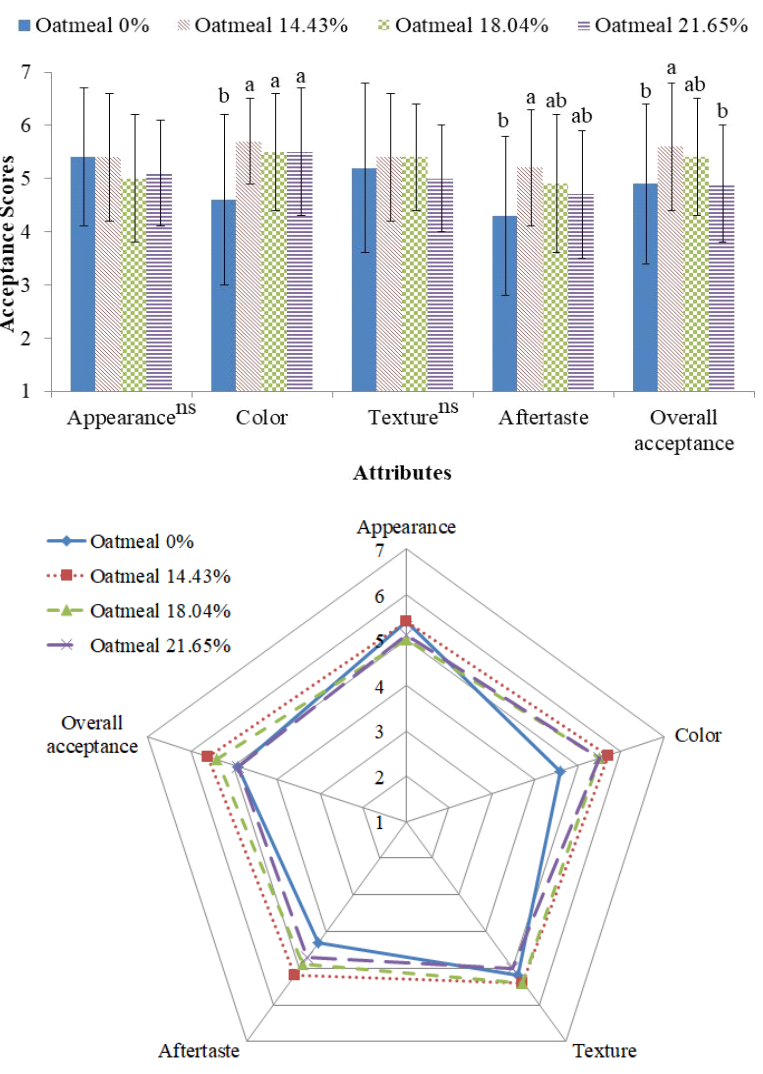

Fig. 5. Acceptance scores of creamy salad dressing with different concentrations of oat meal. Different letters ( $a$ and $b$ ) indicate significant difference among samples at $\mathrm{p}<0.05$. Superscripted ns indicates no significant difference among samples at $\mathrm{p} \geq 0.05$ ( $\mathrm{n}=30$, error bars: standard deviations).

Application of oat dextrine in low-fat mayonnaise at substituted rate for fat at $27.9 \%$ has positive affect on acceptance in viscosity; however, low-fat mayonnaise obtains lower acceptance scores in appearance, taste, and overall acceptability [21]. Addition of oat in fat-reduced ice cream leads to higher acceptance score in flavour, but there is no effect on texture, color, and melting when compared to the control sample [18]. Nevertheless, addition of oat fiber provided negative acceptance effects on aroma and general acceptability in apricot probiotic drinking yogurt [20].

\section{Conclusions}

Substitution of soybean oil with oatmeal resulted in lower fat content but higher protein content and apparent viscosity. At $21.65 \%$ fat replacement, there was $33.13 \%$ fat reduction and $39.58 \%$ higher protein content when compared to the control sample. In sensory evaluation, all reduced-fat creamy salad dressing samples had the same or higher acceptance scores in appearance, color, texture, aftertaste, and overall acceptance. They obtained the acceptance scores of approximately ' 5 ' or 'like slightly'. This research showed good potential for application of oatmeal as a fat replacer in creamy salad dressing. 
This research was funded by Faculty of Applied Science, King Mongkut's University of Technology North Bangkok (KMUTNB), Contract no. 6244104.

\section{References}

1. Z. Ma, J.I. Boye, Food Bioprocess. Tech. 6, 648-670 (2013)

2. Mordor Intelligence, Research report: salad dressing market share - segmented by type (mayonnaise, liquid salad dressing, creamy salad topping and others), applications (home-usage, food service and industrial), and geography - growth, trends and forecasts (2019 - 2024) (Mordor Intelligence, Hyderabad, 2019)

3. Grand View Research, Research report: salad dressings and mayonnaise market analysis, market size, application analysis, regional outlook, competitive strategies, and segment forecasts, 2014 to 2020 (Grand View Research, San Francisco, 2019)

4. A. More, Research report: salad dressing market: global industry research, size, share, growth, trends, and forecast, 2019-2024 (Absolute Reports, Maharashtra, 2019)

5. J.M. Babajide, O.O. Olatunde, World J Dairy Food Sci. 5(1), 25-29 (2010)

6. S.J. Bigornia, S. Saklani, J. Maras, K. Rubin, K.L. Tucker, FASEB J. 30(1), 1154.18 (2016)

7. J. Eke-Ejiofor, F. Owuno, Int J Food Sci Nutr. 3(6), 567-571 (2014)

8. USFDA, U.S Food and U.S. Food and Drug Administration Code of Federal Regulations, Title 21, Part 169. Food dressings and flavorings (U.S. Government Printing Office, Washington, DC, 2012)

9. Z. Ma, J.I. Boye, Food Bioprocess Tech. 6, 648-670 (2013)

10. V.E. Fernandez, G.G. Palazola, N.A. Bosisio, L.M. Martínez, J.R. Wagner, J Food Eng. 111, 57-65 (2012)

11. E.S. Kurtz, W. Wallo, J Drugs Dermatol. 6(2), 167170 (2007)

12. M.B. Andon, J.W. Anderson, Am J Lifestyle Med. 2, 51-57 (2008)

13. M. Ahmad, Z.A. Dar, M. Habib, Sci. Res. Essays 9(4), 52-59 (2014)

14. United States Department of Agriculture, National Nutrient Database for Standard Reference Legacy Release: basic report: 20038, oats (Agricultural Research Service, United States Department of Agriculture, Washington, DC, 2018)
15. H.-S. Yang, G.-D. Kim, S.-G. Choi, S.-T. Joo, Korean J Food Sci Ani Resour. 30(3), 365-372 (2010)

16. S.C. Huang, Y.F. Tsai, C.M. Chen, Asian-Aust J Anim Sci. 24(6), 875-880 (2011)

17. D. Santhi, A. Kalaikannan, J Nutr Food Sci. 4(1), 14 (2014)

18. S.A. Salem, E.M. Hamad, I.S. Ashoush, Food Nutr Sci. 7, 397-404 (2016)

19. Z.S. Ladjevardi, M.S. Yarmand, Z. Emam-Djomeh, A. Niasari-Naslaji, J Agr Sci Technol. 18, 12331246 (2016)

20. M.B. Güler-Akin, I. Ferliarslan, M.S. Akin, Adv Microbiol. 6, 999-1009 (2016)

21. R. Shen, S. Luo, J. Dong, Food Chem. 126, 65-71 (2011)

22. AOAC, Official Methods of Analysis (International, $19^{\text {th }}$ ed. Williams, S). Association of Official Analytical Chemists, Arilington, Virginia. (2012)

23. Fitbit, Inc. Nutritional information, diet info and calories in salad cream dressing, original from Heinz (Fitbit, Inc., San Francisco, 2019)

24. V. Sterna, S. Zute, L. Brunava, Agric Agric Sci Procedia 8, 252-256 (2016)

25. E. Koutsos, A. Gelis, M.S. Echols, Advancements in nutrition and nutritional therapy (Current Therapy in Avian Medicine and Surgery, 2016)

26. T. Sun, Z. Xu, J.S. Godber, W. Prinyawiwatkul, Cereal Chem. 83(4), 451-454 (2006)

27. T. Pintado, A.M. Herrero, F. Jiménez-Colmenero, C.P. Cavalheiro, C. Ruiz-Capillas, Meat Sci. 135, 613 (2018)

28. P. Rasane, A. Jha, L. Sabikhi, A. Kumar, V.S. Unnikrishnan, J Food Sci Technol. 52(2), 662-675 (2015)

29. European Commission, Regulation (EC) No. 41/2009 of 20 January 2009, 21. Concerning the composition and labelling of foodstuffs suitable for people intolerant to gluten (European Commission, Brussels, 2009)

30. M. Lyly, M. Salmenkallio-Marttila, T. Suortti, K. Autio, K. Poutanen, L. Lähteenmäki, Cereal Chem. 80(5), 536-541 (2003)

31. Y. Brummer, C. Defelice, Y. Wu, M. Kwong, P.J. Wood, S.M. Tosh, J Agric Food Chem. 62, 31603167 (2014)

32. N. Sharafbafi, S.M. Tosh, M. Alexander, M. Corredig, Food Hydrocoll. 41, 274-280 (2014)

33. E. Nikoofar, M. Hojjatoleslamy, A. Shakerian, H. Molavi, M.A. Shariaty, Int J Farming Allied Sci. 2(20), 790-796 (2013) 